\title{
Effects of Pumpkin Seed in Men with Lower Urinary Tract Symptoms due to Benign Prostatic Hyperplasia in the One-Year, Randomized, Placebo-Controlled GRANU Study
}

\author{
Winfried Vahlensieck ${ }^{\mathrm{a}}$ Christoph Theurer ${ }^{\mathrm{b}}$ Edith Pfitzer ${ }^{\mathrm{c}}$ Brigitte Patz $^{\mathrm{d}}$ \\ Norbert Banike Udo Engelmann ${ }^{f}$ \\ ${ }^{a}$ Department of Urology, Kurpark Hospital, Bad Nauheim, ${ }^{b}$ Pharmaceutical chemist, Cologne, ${ }^{C}$ Food engineer, \\ Schwäbisch Gmünd, ' Freelance Scientific Consulting, Gäufelden, ${ }^{e}$ Winicker Norimed Medical Research GmbH, \\ Munich, and ${ }^{\mathrm{f}}$ Division of Urologic Oncology, Department of Urology, University of Cologne, Cologne, Germany
}

\section{Key Words}

Benign prostatic hyperplasia - Cucurbita pepo .

International Prostate Symptom Score · Lower urinary

tract symptoms · Pumpkin seed $\cdot$ Quality of life

\begin{abstract}
Introduction: The German Research Activities on Natural Urologicals (GRANU) study was a randomized, partially blinded, placebo-controlled, parallel-group trial that investigated the efficacy of pumpkin seed in men with lower urinary tract symptoms suggestive of benign prostatic hyperplasia (BPH/LUTS). Subjects and Methods: A total of 1,431 men (50-80 years) with BPH/LUTS were randomly assigned to either pumpkin seed ( $5 \mathrm{~g}$ b.i.d.), capsules with pumpkin seed extract (500 $\mathrm{mg}$ b.i.d.) or matching placebo. The primary response criterion was a decrease in International Prostate Symptom Score (IPSS) of $\geq 5$ points from baseline after 12 months. Secondary outcome measures included IPSS-related quality of life, IPSS single items and diary-recorded nocturia. Results: After 12 months, the response rate (intention-to-treat/last-observation-carried-forward approach) did not differ between pumpkin seed ex-
\end{abstract}

tract and placebo. In the case of pumpkin seed (responders: $58.5 \%)$, the difference compared with placebo (responders: 47.3\%) was descriptively significant. The study products were well tolerated. Overall, in men with BPH, 12 months of treatment with pumpkin seed led to a clinically relevant reduction in IPSS compared with placebo. Conclusion: In order to fully justify a recommendation for the use of pumpkin seed to treat moderate LUTS, these findings need to be substantiated in a confirmatory study or systematic review.

(c) 2014 S. Karger AG, Basel

\section{Introduction}

Pumpkin seed has long been used to treat micturition disorders and has found a place in the medical treatment of lower urinary tract symptoms due to benign prostatic hyperplasia (BPH/LUTS) over the past decades [1-3]. The improvement of LUTS in men with BPH was confirmed in clinical practice $[4,5]$.

The seed contains fatty acids ( $\leq 64 \%$ linoleic acid), specific delta-7-sterols, tocopherols and micronutrients [6]. The sterol fraction of pumpkin seed includes the wide-

\section{KARGER 125}

C 2014 S. Karger AG, Base

0042-1138/14/0943-0286\$39.50/0

E-Mail karger@karger.com

www.karger.com/uin
PD Dr. med. Winfried Vahlensieck

Chefarzt der Fachklinik Urologie, Kurpark-Klinik

Kurstrasse 41-45

DE-61231 Bad Nauheim (Germany)

E-Mail winfried.vahlensieck@t-online.de 
spread delta-5-sterols, but the main fraction consists of delta-7-sterols, which are claimed to account for the therapeutic effects and have not been found in other sterolcontaining plant extracts used in $\mathrm{BPH}$ treatment. According to recent analyses, consistently high amounts of delta7-sterols wereonly detected in preparations manufactured from medicinal pumpkin seed [7].

The oral administration of high doses of pumpkin seeds and pumpkin seed oil reduced prostate weight in experimental animal models of prostate growth $[3,8-10]$. The injection of pumpkin seed oil caused reproducible effects on urodynamic parameters in rabbits [11]. Prostatic inflammation has been shown to aggravate LUTS [12]. Therefore, anti-inflammatory effects of pumpkin seed oil as observed in the rat arthritis model [13] may also contribute to clinical improvement. To our knowledge, pumpkin seed extract is the first herbal preparation ever verified in accordance with the clinical research criteria of the International Consultation on BPH [14]. A 1-year-long, placebo-controlled study including $465 \mathrm{pa}$ tients and using the International Prostate Symptom Score (IPSS) as the primary endpoint demonstrated statistically significant improvements compared with placebo. The pumpkin seed extract used is therefore recommended by the author for the treatment of BPH/LUTS of mild-to-moderate severity [15].

The German Research Activities on Natural Urologicals (GRANU) study was planned in consultation with the German Federal Institute for Drugs and Medical Devices to demonstrate the efficacy of pumpkin seed in men with BPH/LUTS. In accordance with the criteria of the International Consultation on $\mathrm{BPH}$, a placebo-controlled design was considered the most suitable, since considerable symptomatic improvement had been demonstrated with placebo. Therefore, the present three-armed study compared pumpkin seed and pumpkin seed extract with placebo in parallel groups.

\section{Subjects and Methods}

The study was performed by German urologists in private practice in accordance with good clinical practice and the Declaration of Helsinki. The study protocol was approved by the responsible ethics committee and the Federal Institute for Drugs and Medical Devices (BfArM). All patients gave written informed consent.

\section{Participants}

Men between 50 and 80 years old with BPH/LUTS for $\geq 6$ months were recruited if they had either never received any treatment (phytotherapeutic agents, $\alpha$-adrenergic blocking agents and 5- $\alpha$-reductase inhibitors) or had stopped such treatment $\geq 6$ months prior to enrolment. Patients eligible for randomization had an IPSS $\geq 13$ and $\leq 19$, IPSS-related quality of life (QoL) $\geq 3$, diary-recorded nocturia $\geq 2$ times and peak urinary flow rate $\left(\mathrm{Q}_{\max }\right) \leq 12 \mathrm{ml} / \mathrm{s}$ (voided volume: $\geq 150 \mathrm{ml}$ ).

Exclusion criteria were prostate volume $>40 \mathrm{ml}$ or post-void residual volume (PVR) $>100 \mathrm{ml}$. Further exclusion criteria and prohibited concomitant medications followed the recommendations of the International Consultation on BPH [14-16]. As antiinflammatory mechanisms are postulated for herbal substances, concomitant use of NSAIDs was also prohibited.

\section{Study Medication}

Active medications were purified pumpkin seed (brand name: GRANU FINK ${ }^{\circledR}$ Kürbiskerne) or pumpkin seed extract (500 mg each capsule; former brand name: PROSTA FINK ${ }^{\circledR}$ FORTE $500 \mathrm{mg}$; current name: GRANU FINK Prosta forte $500 \mathrm{mg}$ ); both are registered medicinal products in Germany and manufactured from medicinal pumpkin seed (GRANU FINK Arzneikürbis), a special, company-owned, registered cultivar of Cucurbita pepo L. convar. citrullinina GREB. var. styriaca GREB. Extraction with ethanol $92 \%(\mathrm{w} / \mathrm{w})$ gives a semisolid extract with a drug-extract ratio of 15-25:1. The total daily dose was $10 \mathrm{~g}$ pumpkin seed $(2 \times$ $5 \mathrm{~g}$ ) or 2 capsules with pumpkin seed extract. The patients took the study medication in the morning and the evening.

\section{Randomization and Treatment}

After a 1-month run-in period without treatment, eligible patients were assigned to receive either pumpkin seed or pumpkin seed extract or placebo (1:1:1). The contract statistician had generated the block randomization schedule (stratified by site) using SAS PROC PLAN. The block size was not stated in the protocol. To ensure allocation concealment, the sealed randomization envelopes were not opened before the moment of assignment.

\section{Study Procedure}

At the screening visit, the patients underwent a physical examination as well as laboratory tests including prostate-specific antigen (PSA), uroflowmetry and sonographic measurements of prostate volume and PVR. Concomitant diseases and medications were recorded, and the IPSS and IPSS-related QoL were assessed. Potentially suitable patients were given a micturition diary to assess nocturia and asked to return after 1 month. At the baseline visit, the patients returned the micturition diary and completed the IPSS questionnaire including IPSS-related QoL. The investigator reviewed the inclusion and exclusion criteria and assigned eligible patients to one of the three treatment groups by opening the randomization envelopes in ascending order. Four post-randomization visits were scheduled after 3, 6, 9 and 12 months to assess IPSS, QoL and diaryrecorded nocturia. At all visits, blood pressure, concomitant medications and adverse events were recorded. At the final visit, all the examinations and tests performed at screening were repeated.

\section{Outcomes}

The primary endpoint was the response rate defined as the proportion of patients with a decrease of $\geq 5$ points on the IPSS after 12 months of treatment. Secondary outcomes included changes in IPSS (total score and 7 single items), nocturia and IPSS-related QoL. Safety and tolerability were assessed by laboratory tests, urological examinations and the evaluation of adverse events. 
Fig. 1. Subject disposition. ${ }^{*}$ One patient was randomized to the placebo group but did not take any medication and therefore was excluded from the ITT population.

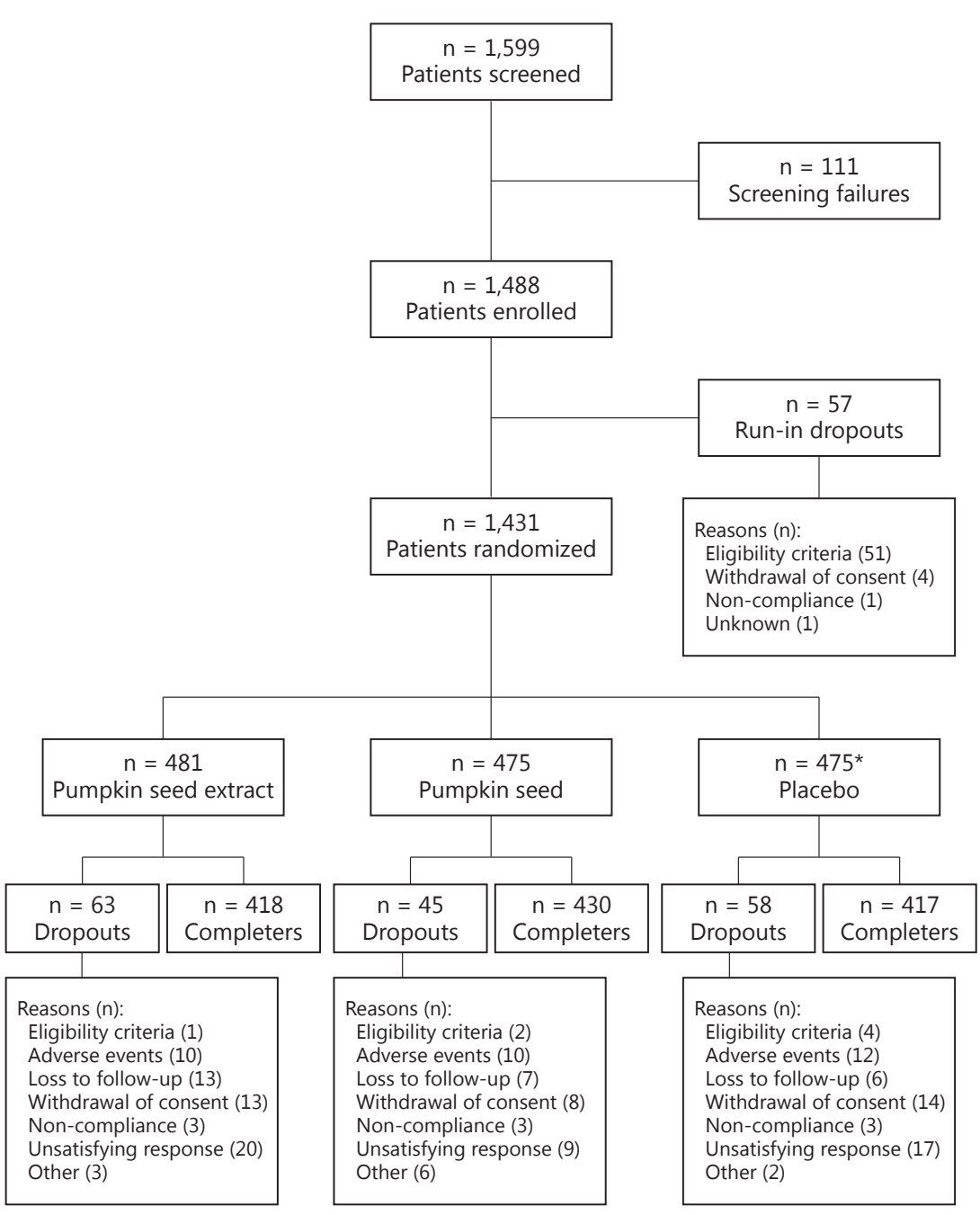

\section{Sample Size Calculation}

Based on a two-sided $\alpha$-level of 0.05 , a power of $90 \%$ and the assumption of a $10 \%$ difference in response rate compared with placebo, 1,590 men were to be randomized, and in order to account for a run-in dropout rate of up to $10 \%$, a total of 1,770 patients were to be screened. To control for multiplicity, a hierarchical testing procedure was set up for the primary efficacy endpoint. In this procedure, placebo was to be compared firstly with pumpkin seed extract and subsequently (only if statistical significance was demonstrated at this level) with pumpkin seed.

\section{Statistical Analysis}

All data analyses were performed in accordance with a statistical analysis plan pre-established before enrolment. All the staff involved in study analyses (data managers and statisticians) was unaware of the treatment assignment and the randomized sequence list. Study centres with a low number of enrolled patients were pooled before unblinding. SAS software (German version 9.2) was used for analysis.

The primary analysis was performed according to the intention-to-treat (ITT) principle using the last-observation-carriedforward (LOCF) approach. The ITT population was defined as all the patients who took at least 1 dose of the study medication. All analyses were repeated for the PP population. An independent, blinded, third-party review committee was responsible for patients' allocation to the PP set.

Response rates and 95\% CI according to Clopper-Pearson were estimated. The proportion of responders was compared across the treatment groups using the Cochran-Mantel-Haenszel procedure complemented by the Breslow-Day test to estimate site-by-treatment interactions. Confirmatory and descriptive analyses were performed. In the hierarchical confirmatory strategy for the primary efficacy endpoint, the effect of pumpkin seed extract versus placebo was tested first because the pumpkin seed 
Table 1. Demographic characteristics and outcome measures at baseline (ITT set)

\begin{tabular}{|c|c|c|c|}
\hline Parameter & $\begin{array}{l}\text { Pumpkin seed extract } \\
(\mathrm{n}=481)\end{array}$ & $\begin{array}{l}\text { Pumpkin seed } \\
(\mathrm{n}=475)\end{array}$ & $\begin{array}{l}\text { Placebo } \\
(\mathrm{n}=474)\end{array}$ \\
\hline \multicolumn{4}{|l|}{ Age } \\
\hline Observations, $\mathrm{n}$ & 481 & 475 & 474 \\
\hline Mean $\pm S D$, years & $65.2 \pm 6.9$ & $65.2 \pm 7.0$ & $65.5 \pm 6.8$ \\
\hline Median (range), years & $66.0(45.0-80.0)$ & $66.0(50.0-80.0)$ & $66.0(47.0-82.0)$ \\
\hline \multicolumn{4}{|l|}{ IPSS total ${ }^{\mathrm{a}}$} \\
\hline Observations, $\mathrm{n}$ & 471 & 470 & 467 \\
\hline Mean \pm SD & $16.0 \pm 2.1$ & $16.0 \pm 2.1$ & $16.1 \pm 1.9$ \\
\hline Median (range) & $16.0(5.0-22.0)$ & $16.0(12.0-31.0)$ & $16.0(11.0-23.0)$ \\
\hline \multicolumn{4}{|l|}{ IPSS-QoL } \\
\hline Observations, $\mathrm{n}$ & 472 & 466 & 469 \\
\hline Mean \pm SD & $3.5 \pm 0.7$ & $3.5 \pm 0.7$ & $3.5 \pm 0.7$ \\
\hline Median (range) & $3.0(0.0-6.0)$ & $3.0(2.0-6.0)$ & $3.0(2.0-6.0)$ \\
\hline \multicolumn{4}{|l|}{ Nocturia $^{b}$} \\
\hline Observations, $\mathrm{n}$ & 481 & 474 & 472 \\
\hline Mean \pm SD & $2.6 \pm 0.8$ & $2.6 \pm 0.8$ & $2.7 \pm 0.8$ \\
\hline Median (range) & $2.0(0.0-6.0)$ & $2.0(1.0-6.0)$ & $3.0(0.0-6.0)$ \\
\hline \multicolumn{4}{|l|}{ Duration of symptoms } \\
\hline Observations, $\mathrm{n}$ & 312 & 315 & 320 \\
\hline Mean $\pm S D$, years & $4.4 \pm 3.5$ & $4.0 \pm 3.5$ & $4.5 \pm 3.3$ \\
\hline Median (range), years & $3.2(0.2-15.0)$ & $2.6(0.5-16.1)$ & $3.7(0.0-17.7)$ \\
\hline \multicolumn{4}{|l|}{ Prostate size } \\
\hline Observations, $\mathrm{n}$ & 468 & 467 & 468 \\
\hline Mean $\pm \mathrm{SD}, \mathrm{cm}^{3}$ & $29.0 \pm 7.7$ & $28.6 \pm 7.3$ & $28.0 \pm 7.3$ \\
\hline Median (range), $\mathrm{cm}^{3}$ & $30(10-52)$ & $30(10-45)$ & $30(10-53)$ \\
\hline \multicolumn{4}{|l|}{ PVR } \\
\hline Observations, $\mathrm{n}$ & 479 & 475 & 473 \\
\hline Mean $\pm \mathrm{SD}, \mathrm{ml}$ & $33.5 \pm 28.3$ & $33.0 \pm 26.8$ & $34.8 \pm 27.9$ \\
\hline Median (range), ml & $30(0-100)$ & $30(0-100)$ & $30(0-100)$ \\
\hline \multicolumn{4}{|l|}{ Uroflow: $\mathrm{Q}_{\max }$} \\
\hline Observations, $\mathrm{n}$ & 475 & 473 & 473 \\
\hline Mean $\pm \mathrm{SD}, \mathrm{ml} / \mathrm{s}$ & $9.5 \pm 2.4$ & $9.6 \pm 1.9$ & $9.8 \pm 2.6$ \\
\hline Median (range), $\mathrm{ml} / \mathrm{s}$ & $10(2-36)$ & $10(4-16)$ & $10(4-27)$ \\
\hline \multicolumn{4}{|l|}{ Uroflow: volume } \\
\hline Observations, $\mathrm{n}$ & 476 & 473 & 473 \\
\hline Mean \pm SD, ml & $237 \pm 91$ & $237 \pm 96$ & $235 \pm 89$ \\
\hline Median (range), ml & $206(16-724)$ & $210(21-793)$ & $208(32-648)$ \\
\hline
\end{tabular}

\footnotetext{
${ }^{a}$ Homogeneity of IPSS across the groups was assessed by use of the Kruskal-Wallis test; $\mathrm{p}=0.216 .{ }^{\mathrm{b}}$ Nocturia: mean values over 3 nights recorded by micturition diary before the baseline visit.
}

extract was given in a double-blinded manner. The subsequent comparison of pumpkin seed with placebo was to be carried out only if the first comparison had demonstrated efficacy. The purpose of this strategy was, firstly, to strengthen the credibility of the results for the comparison between placebo and pumpkin seed, which could not be blinded, and, secondly, to reduce the overall study sample size.

In the case of secondary outcomes, laboratory tests and urological examinations, descriptive statistical parameters of absolute and relative differences compared with baseline were calculated for each treatment group. Safety and tolerability were evaluated on the basis of reported adverse events.

Effects of Pumpkin Seed in Men with LUTS due to BPH

\section{Results}

A total of 267 study centres were initiated, and between July 2005 and June 2008, a total of 158 study sites screened 1,599 patients for eligibility. Of these, 1,431 were randomly assigned to one of the three treatment groups (fig. 1). Their baseline characteristics are shown in table 1. There were no differences between the groups in terms of treatment duration or dropout rate $(\mathrm{p}=0.181$; Fisher's exact test). The PP set consisted of 908 patients (table 2). 
Table 2. Major protocol violations with a frequency $\geq 3.0 \%$ in all randomized patients

\begin{tabular}{lllc}
\hline & $\begin{array}{l}\text { Pumpkin seed extract } \\
(\mathrm{n}=481 ; \text { ITT })\end{array}$ & $\begin{array}{l}\text { Pumpkin seed } \\
(\mathrm{n}=475 ; \text { ITT })\end{array}$ & $\begin{array}{l}\text { Placebo } \\
(\mathrm{n}=475 ; \text { ITT })\end{array}$ \\
\hline Patients excluded from PP analysis & $174(36.2)$ & $184(38.7)$ & $165(34.7)$ \\
\hline Non-compliance & $27(5.6)$ & $81(17.1)$ & $28(5.9)$ \\
Deviation from treatment schedule at visit 6 & $39(8.1)$ & $26(5.5)$ & $37(7.8)$ \\
Withdrawal for non-medicinal reasons & $33(6.9)$ & $26(5.5)$ & $29(6.1)$ \\
Randomization error & $30(6.2)$ & $26(5.5)$ & $27(5.7)$ \\
Absence of any IPSS value after baseline & $28(5.8)$ & $21(4.4)$ & $16(3.4)$ \\
Prohibited concomitant medication & $24(5.0)$ & $15(3.2)$ & $17(3.6)$ \\
Diseases likely to affect micturition & $13(2.7)$ & $13(2.7)$ & $18(3.8)$ \\
\hline
\end{tabular}

Values denote numbers with percentages in parentheses. Multiple options were possible per patient.

${ }^{a}$ After 12 months of treatment.

Table 3. OR analyses of IPSS response rates (LOCF: ITT and PP) after 12 months of treatment

\begin{tabular}{|c|c|c|c|c|}
\hline \multirow[t]{2}{*}{ Compared groups } & \multicolumn{2}{|l|}{ OR } & \multicolumn{2}{|l|}{$\mathrm{p}$ value } \\
\hline & value & $95 \% \mathrm{CI}^{\mathrm{a}}$ & $\mathrm{M}-\mathrm{H} \chi^{2}$ test & $\mathrm{B}-\mathrm{D}$ test $^{\mathrm{b}}$ \\
\hline \multicolumn{5}{|l|}{ ITT (LOCF) analysis } \\
\hline Placebo vs. PS extract ${ }^{c}$ & 1.06 & $0.82-1.37$ & 0.65 & 0.68 \\
\hline Placebo vs. PS ${ }^{c}$ & 0.65 & $0.50-0.84$ & $<0.01^{\mathrm{d}}$ & 0.33 \\
\hline PS vs. PS extract & 1.64 & $1.26-2.12$ & $<0.01^{\mathrm{e}}$ & 0.35 \\
\hline \multicolumn{5}{|l|}{ PP (LOCF) analysis } \\
\hline Placebo vs. PS extract & 0.94 & $0.69-1.29$ & $0.72^{\mathrm{e}}$ & 0.22 \\
\hline Placebo vs. PS & 0.68 & $0.49-0.93$ & $0.02^{\mathrm{e}}$ & 0.34 \\
\hline PS vs. PS extract & 1.40 & $1.01-1.93$ & $0.04^{\mathrm{e}}$ & 0.09 \\
\hline
\end{tabular}

B-D = Breslow-Day; M-H = Mantel-Haenszel; PS = pumpkin seed.

${ }^{\mathrm{a}} \mathrm{CI}$ were estimated according to Clopper-Pearson. ${ }^{\mathrm{b}}$ The homogeneity of the OR across the sites was estimated by means of the Breslow-Day test with the Tyrone correction $(\alpha$-level, $\mathrm{p}<0.1)$. ${ }^{\mathrm{c}}$ These comparisons belong to the primary confirmatory hierarchical test procedure. ${ }^{\mathrm{d}}$ As the analysis was performed in 2 steps, the results of step 2 are interpreted descriptively as a consequence of the non-significant result of step 1 (placebo vs. PS extract). ${ }^{\mathrm{e}}$ Descriptive $\mathrm{p}$ values.

\section{Primary Outcome}

In the ITT cohort (LOCF), the response rate did not differ significantly between the double-blinded groups but was significantly (about 10\%) higher in the pumpkin seed group (tables 3,4 ). This statistical significance is descriptive only, as the confirmatory statistical testing strategy was stopped after the non-significant result for the comparison between pumpkin seed extract and placebo. The IPSS response rate as observed increased by $6 \%$ during treatment with pumpkin seed extract (for placebo: $2 \%$ relative change to ITT-LOCF; table 4 , fig. 2).

\section{Secondary Outcomes}

The mean IPSS decreased continuously in all groups from month 3 onwards (fig. 2, table 5). After the 1-year treatment period, the mean differences compared with baseline for the ITT-LOCF population were $-5.4 \pm 5.1$, $-4.2 \pm 5.4$ and $-4.0 \pm 5.5$ with pumpkin seed, pumpkin seed extract and placebo, respectively. For the PP population, the differences were $-5.5 \pm 5.2$ (pumpkin seed), $-4.6 \pm 5.6$ (pumpkin seed extract) and $-4.2 \pm 5.6$ (placebo).

At the study end, only $10.2 \%$ of the patients treated with pumpkin seed reported a worsening of their symp- 
Table 4. IPSS response rates after 12 months of treatment (visit 6)

\begin{tabular}{|c|c|c|c|c|c|c|}
\hline \multirow[t]{3}{*}{ Treatment group } & \multicolumn{6}{|c|}{ IPSS response rate } \\
\hline & \multicolumn{3}{|c|}{ ITT population } & \multicolumn{3}{|c|}{ PP population } \\
\hline & total, $\mathrm{n}$ & $\mathrm{n}(\%)$ & $95 \%$ CI & total, $\mathrm{n}$ & $\mathrm{n}(\%)$ & $95 \% \mathrm{CI}$ \\
\hline \multicolumn{7}{|l|}{ Pumpkin seed extract } \\
\hline Visit 6 (as observed) & 396 & $195(49.2)$ & $44.2-54.3$ & 289 & $151(52.2)$ & $46.3-58.1$ \\
\hline Visit 6 (LOCF) & 471 & $218(46.3)$ & $41.7-50.9$ & 307 & $155(50.5)$ & $44.8-56.2$ \\
\hline \multicolumn{7}{|l|}{ Pumpkin seed } \\
\hline Visit 6 (as observed) & 422 & $259(61.4)$ & $56.5-66.0$ & 280 & $166(59.3)$ & $53.3-65.1$ \\
\hline Visit 6 (LOCF) & 470 & $275(58.5)$ & $53.9-63.0$ & 291 & $171(58.8)$ & $52.9-64.5$ \\
\hline \multicolumn{7}{|l|}{ Placebo } \\
\hline Visit 6 (as observed) & 402 & $203(50.5)$ & $45.5-55.5$ & 289 & $144(49.8)$ & $43.9-55.7$ \\
\hline Visit 6 (LOCF) & 467 & $223(47.8)$ & $43.1-52.4$ & 310 & $152(49.0)$ & $43.3-54.7$ \\
\hline
\end{tabular}

Table 5. IPSS data for all study visits

\begin{tabular}{|c|c|c|c|c|c|c|}
\hline \multirow[t]{3}{*}{ Treatment group } & \multicolumn{6}{|c|}{ Total IPSS } \\
\hline & \multicolumn{3}{|c|}{ ITT population } & \multicolumn{3}{|c|}{ PP population } \\
\hline & total, $\mathrm{n}$ & mean $\pm \mathrm{SD}$ & median & total, $\mathrm{n}$ & mean $\pm S D$ & median \\
\hline \multicolumn{7}{|l|}{ Pumpkin seed extract } \\
\hline Visit 1 (screening) & 474 & $15.8 \pm 1.9$ & 16.0 & 305 & $15.8 \pm 1.9$ & 16.0 \\
\hline Visit 2 (baseline) & 471 & $16.0 \pm 2.1$ & 16.0 & 307 & $16.0 \pm 1.8$ & 16.0 \\
\hline Visit 3 (3 months) & 455 & $12.8 \pm 4.6$ & 13.0 & 302 & $12.9 \pm 4.5$ & 13.0 \\
\hline Visit 4 (6 months) & 442 & $11.9 \pm 4.9$ & 12.0 & 301 & $11.9 \pm 4.6$ & 12.0 \\
\hline Visit 5 (9 months) & 428 & $11.8 \pm 5.2$ & 12.0 & 294 & $11.7 \pm 5.0$ & 12.0 \\
\hline Visit $6(12 \text { months })^{\mathrm{a}}$ & 404 & $11.4 \pm 5.5$ & 11.0 & 289 & $11.2 \pm 5.5$ & 11.0 \\
\hline Visit 6 (LOCF) & 480 & $11.7 \pm 5.5$ & 12.0 & 307 & $11.4 \pm 5.5$ & 11.0 \\
\hline \multicolumn{7}{|l|}{ Pumpkin seed } \\
\hline Visit 1 (screening) & 471 & $15.9 \pm 1.8$ & 16.0 & 290 & $15.9 \pm 1.8$ & 16.0 \\
\hline Visit 2 (baseline) & 470 & $16.0 \pm 2.1$ & 16.0 & 291 & $15.9 \pm 1.8$ & 16.0 \\
\hline Visit 3 (3 months) & 449 & $12.3 \pm 4.6$ & 12.0 & 286 & $12.4 \pm 4.6$ & 13.0 \\
\hline Visit 4 (6 months) & 446 & $11.1 \pm 4.7$ & 11.0 & 286 & $11.2 \pm 4.8$ & 11.0 \\
\hline Visit 5 (9 months) & 434 & $10.5 \pm 4.8$ & 10.0 & 284 & $10.4 \pm 4.6$ & 10.0 \\
\hline Visit $6(12 \text { months })^{\mathrm{a}}$ & 425 & $10.2 \pm 5.1$ & 10.0 & 280 & $10.3 \pm 5.1$ & 10.0 \\
\hline Visit 6 (LOCF) & 475 & $10.6 \pm 5.2$ & 10.0 & 291 & $10.4 \pm 5.2$ & 10.0 \\
\hline \multicolumn{7}{|l|}{ Placebo } \\
\hline Visit 1 (screening) & 471 & $16.1 \pm 1.9$ & 16.0 & 310 & $16.0 \pm 1.8$ & 16.0 \\
\hline Visit 2 (baseline) & 467 & $16.1 \pm 1.9$ & 16.0 & 310 & $16.1 \pm 1.8$ & 16.0 \\
\hline Visit 3 (3 months) & 461 & $13.2 \pm 4.7$ & 13.0 & 308 & $13.1 \pm 4.6$ & 13.0 \\
\hline Visit 4 (6 months) & 440 & $12.3 \pm 5.0$ & 12.0 & 304 & $12.1 \pm 5.1$ & 12.0 \\
\hline Visit 5 (9 months) & 425 & $12.0 \pm 5.3$ & 12.0 & 299 & $11.8 \pm 5.4$ & 12.0 \\
\hline Visit $6(12 \text { months })^{\mathrm{a}}$ & 407 & $11.7 \pm 5.4$ & 11.0 & 289 & $11.7 \pm 5.5$ & 11.0 \\
\hline Visit 6 (LOCF) & 474 & $12.1 \pm 5.6$ & 12.0 & 310 & $11.9 \pm 5.7$ & 11.0 \\
\hline
\end{tabular}


Table 6. Proportion of patients with improvement, no change or worsening of the IPSS compared with baseline and cumulative frequency of IPSS decrease from baseline after 12 months of treatment

\begin{tabular}{|c|c|c|c|c|c|c|}
\hline & \multicolumn{2}{|c|}{ Pumpkin seed extract } & \multicolumn{2}{|c|}{ Pumpkin seed } & \multicolumn{2}{|l|}{ Placebo } \\
\hline Any improvement ( $\geq 1$ point) & $362(76.9)$ & $248(80.8)$ & $382(81.3)$ & $239(82.1)$ & $349(74.7)$ & $235(75.8)$ \\
\hline No change & $37(7.9)$ & $12(3.9)$ & $40(8.5)$ & $18(6.2)$ & $26(5.6)$ & $14(4.5)$ \\
\hline Worsening & $72(15.3)$ & $47(15.3)$ & $48(10.2)$ & $34(11.7)$ & $92(19.7)$ & $61(19.7)$ \\
\hline$\geq 7$ points & $159(33.8)$ & $166(37.8)$ & $221(47.0)$ & $136(46.7)$ & $164(35.1)$ & $118(38.1)$ \\
\hline$\geq 5$ points $\left(\right.$ responders $\left.{ }^{\mathrm{a}}\right)$ & $218(46.3)$ & $155(50.5)$ & $275(58.5)$ & $171(58.8)$ & $223(47.8)$ & $152(49.0)$ \\
\hline$\geq 3$ points & $291(61.8)$ & $204(66.4)$ & $328(69.8)$ & $205(70.4)$ & $286(61.2)$ & $195(62.9)$ \\
\hline
\end{tabular}

Values denote numbers of patients with percentages in parentheses.

${ }^{a} \mathrm{p}$ values are presented in table 3.

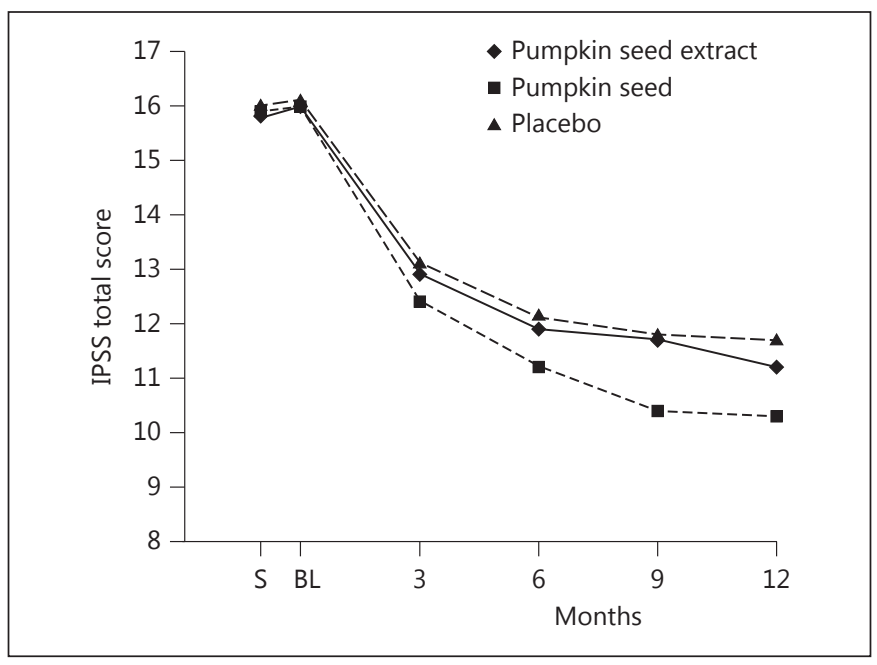

Fig. 2. Mean IPSS total scores during randomized treatment over 12 months. PP analysis set as observed. $\mathrm{S}=$ Screening visit; $\mathrm{BL}=$ baseline, 1 month after screening.

toms (15.3 and $19.7 \%$ with pumpkin seed extract and placebo, respectively) (table 6). After 12 months, all individual symptoms had improved in all groups, and in the pumpkin seed group, the relief of urgency, incomplete emptying and weak stream by $1.0,0.9$ and 0.9 points, respectively, accounted for most of the total IPSS change from baseline.

The mean values for diary-recorded nocturia and IPSS-related QoL decreased continuously over time in all study groups. At the study end, the mean decrease in nocturia from baseline was 1.0, 0.9 and 0.8 with pumpkin seed, pumpkin seed extract and placebo, respectively

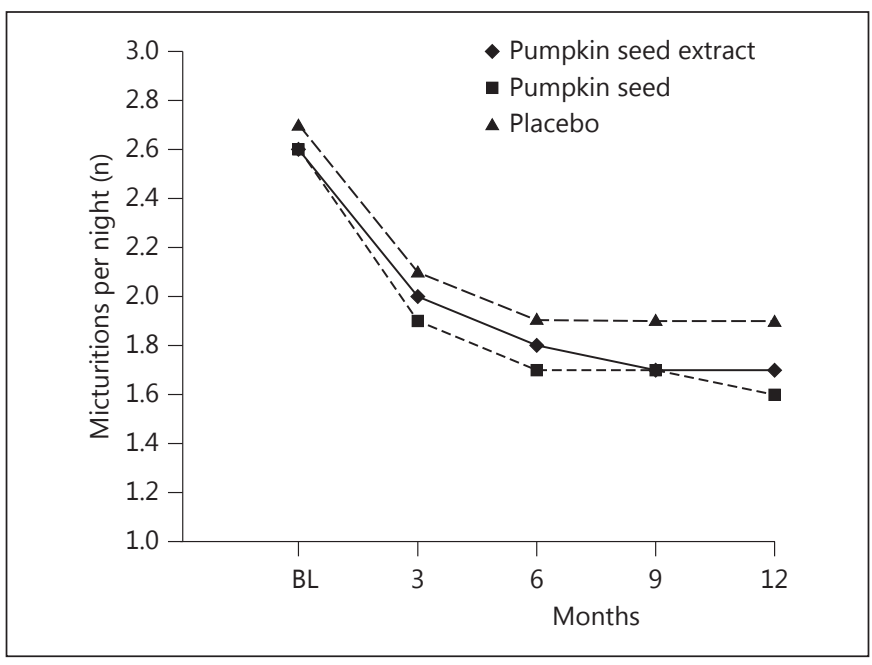

Fig. 3. Mean values for nocturia according to diary before baseline and at post-randomization visits over 12 months (ITT set). For each patient the mean value over 3 nights was calculated. Mean differences \pm SD from baseline after 12 months: $-1.0 \pm 0.9$ (pumpkin seed), $-0.9 \pm 0.9$ (pumpkin seed extract) and $-0.8 \pm 1.0$ (placebo). $\mathrm{BL}=$ Baseline.

(fig. 3). QoL improved, on average, by 36.0, 33.4 and $29.2 \%$ with pumpkin seed, pumpkin seed extract and placebo, respectively (fig. 4).

\section{Safety and Tolerability}

On average, the $\mathrm{Q}_{\max }$ increased by $4.3,3.6$ and $3.6 \mathrm{ml} / \mathrm{s}$ (means of relative differences: 49.1, 45.1 and $41.7 \%$ ) with pumpkin seed, pumpkin seed extract and placebo, respectively (table 7). As expected, there was no clinically 
Table 7. Results of urological examinations and serum PSA levels at the screening and the final visit (after 12 months or at the time of last observation for dropout patients) for the safety population

\begin{tabular}{|c|c|c|c|c|c|c|}
\hline \multirow[t]{2}{*}{ Parameter } & \multicolumn{2}{|c|}{ Pumpkin seed extract } & \multicolumn{2}{|c|}{ Pumpkin seed } & \multicolumn{2}{|c|}{ Placebo } \\
\hline & $\mathrm{n}$ & $\begin{array}{l}\text { mean } \pm \mathrm{SD} \\
(\text { median })\end{array}$ & $\mathrm{n}$ & $\begin{array}{l}\text { mean } \pm \text { SD } \\
\text { (median) }\end{array}$ & $\mathrm{n}$ & $\begin{array}{l}\text { mean } \pm \mathrm{SD} \\
(\text { median })\end{array}$ \\
\hline \multicolumn{7}{|l|}{ Uroflow $\mathrm{Q}_{\max }, \mathrm{ml} / \mathrm{s}$} \\
\hline Visit 1 (screening) & 475 & $9.5 \pm 2.4(10.0)$ & 473 & $9.6 \pm 1.9(10.0)$ & 474 & $9.8 \pm 2.6(10.0)$ \\
\hline Visit 6 (final) & 408 & $13.3 \pm 6.5(12.0)$ & 412 & $13.8 \pm 6.9(12.0)$ & 406 & $13.3 \pm 6.5(12.0)$ \\
\hline Difference $^{\mathrm{a}}$ & 406 & $3.6 \pm 6.3(2.6)$ & 412 & $4.3 \pm 6.8(3.0)$ & 406 & $3.6 \pm 6.4(2.0)$ \\
\hline \multicolumn{7}{|l|}{ Voided volume, $\mathrm{ml}$} \\
\hline Visit 1 (screening) & 476 & $237 \pm 91(206)$ & 473 & $237 \pm 96(210)$ & 474 & $235 \pm 89(208)$ \\
\hline Visit 6 (final) & 408 & $230 \pm 122(209)$ & 412 & $234 \pm 135(208)$ & 406 & $242 \pm 143(209)$ \\
\hline Difference $^{\mathrm{a}}$ & 406 & $-7 \pm 131(-3)$ & 412 & $-4 \pm 138(-10)$ & 406 & $4 \pm 148(-2)$ \\
\hline \multicolumn{7}{|l|}{ Prostate size, $\mathrm{ml}$} \\
\hline Visit 1 (screening) & 468 & $29.0 \pm 7.7(30.0)$ & 467 & $28.6 \pm 7.3(30.0)$ & 469 & $29.1 \pm 7.4(30.0)$ \\
\hline Visit 6 (final) & 417 & $31.2 \pm 11.8(30.0)$ & 424 & $31.3 \pm 11.5(30.0)$ & 416 & $31.4 \pm 12.2(30.0)$ \\
\hline Difference $^{\mathrm{a}}$ & 410 & $2.3 \pm 9.7(1.0)$ & 420 & $2.7 \pm 8.8(1.0)$ & 413 & $2.6 \pm 10.2(2.0)$ \\
\hline \multicolumn{7}{|l|}{ PVR, ml } \\
\hline Visit 1 (screening) & 479 & $33.5 \pm 28.3(30.0)$ & 475 & $33.0 \pm 26.8(30.0)$ & 474 & $34.8 \pm 27.9(30.0)$ \\
\hline Visit 6 (final) & 421 & $31.9 \pm 38.2(25.0)$ & 432 & $30.6 \pm 34.6(22.0)$ & 420 & $35.0 \pm 40.8(27.0)$ \\
\hline Difference $^{a}$ & 421 & $-1.8 \pm 41.2(0.0)$ & 432 & $-2.4 \pm 35.7(0.0)$ & 420 & $1.2 \pm 41.1(0.0)$ \\
\hline \multicolumn{7}{|l|}{ PSA, ng/ml } \\
\hline Visit 1 (screening) & 481 & $1.7 \pm 1.5(1.3)$ & 474 & $1.8 \pm 1.6(1.3)$ & 474 & $1.9 \pm 1.6(1.3)$ \\
\hline Visit 6 (final) & 421 & $1.9 \pm 1.7(1.3)$ & 433 & $2.0 \pm 1.9(1.4)$ & 428 & $2.0 \pm 1.8(1.4)$ \\
\hline Difference $^{\mathrm{a}}$ & 421 & $0.1 \pm 1.1(0.0)$ & 433 & $0.2 \pm 1.0(0.1)$ & 428 & $0.2 \pm 0.9(0.1)$ \\
\hline
\end{tabular}

${ }^{a}$ Individual difference $=$ value at visit 6 - value at visit 1.

significant change in mean prostate volume in any of the groups. No relevant changes in PVR or PSA levels were observed (table 7).

Of the 1,431 patients, $284(19.1 \%)$ reported at least one adverse event without relevant differences between the groups in distribution by system organ classes. Only $2.2 \%$ of the patients discontinued the study due to adverse events. Serious events, all of them to be expected in this age group and not related to the study medication, occurred in 67 patients $(4.5 \%)$. Blood pressure, heart rate and safety laboratory results showed only marginal variations.

Only 13 non-serious adverse events, most of them gastrointestinal disorders, were judged by the investigators to be possibly drug related. These events were reported by 8 patients, of whom 3, 2 and 3 had been treated with pumpkin seed, pumpkin seed extract and placebo, respectively. Of these patients, 1 in the pumpkin seed group and 1 in the placebo group discontinued the study.

Effects of Pumpkin Seed in Men with LUTS due to BPH

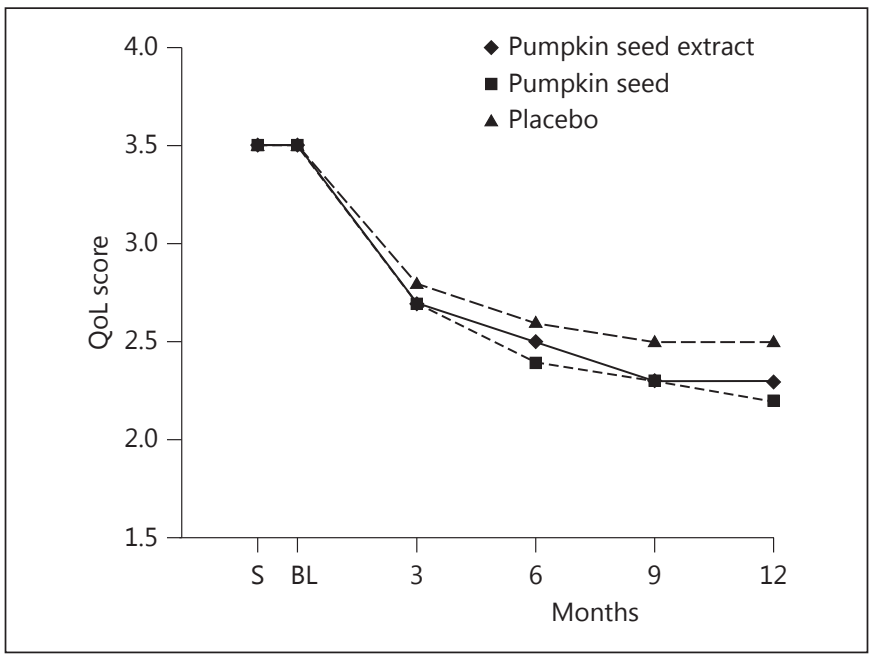

Fig. 4. Mean IPSS-related QoL (ITT set). Scores range from $0=$ 'delighted' to $6=$ 'terrible'. Mean differences \pm SD from baseline after 12 months: $-1.3 \pm 1.1$ (pumpkin seed), $-1.2 \pm 1.2$ (pumpkin seed extract) and $-1.0 \pm 1.2$ (placebo). $\mathrm{S}=$ Screening visit; $\mathrm{BL}=$ baseline, 1 month after screening. 


\section{Discussion}

Recent studies comparing herbal preparations with synthetic drugs have been barely accepted by the scientific community due to the lack of a placebo control and/ or inadequate power $[16,17]$. In this specific three-armed trial, we presented a design to compare the efficacy of unprocessed pumpkin seed with that of placebo treatment. The randomization procedure resulted in well-balanced baseline characteristics between the groups. The patients had $\geq 13$ IPSS points and their QoL score was $\geq 3$; therefore, they had symptoms bothersome enough to seek treatment. The responders had an IPSS improvement by $\geq 5$ points, and so they unequivocally experienced a clinically significant symptom relief. According to previous symptom evaluations, a minimum improvement of 3 points is necessary for a patient to perceive a clinical benefit $[18,19]$.

The inclusion criteria were strictly in accordance with the recommendations of the International Consultation on BPH (IPSS $\geq 13$, QoL $\geq 3$ and $\mathrm{Q}_{\max } \leq 12 \mathrm{ml} / \mathrm{s}$ ) [14]. As this study was placebo controlled, the ethics committee tightened these selection criteria by limiting IPSS to 19 points, prostate volume to $40 \mathrm{ml}$ and PVR to $100 \mathrm{ml}$. In addition, a number of eligible patients did not accept placebo treatment. Patient recruitment therefore progressed with difficulties, and only $60 \%$ of the initiated study sites were able to identify eligible patients.

A total of 1,431 patients, equivalent to $90 \%$ of the calculated sample size, were eventually randomized. The scale of this study is similar to that of well-conducted trials on BPH with synthetic drugs [20]. It easily exceeds that of controlled studies of herbal products in general, and in particular those with a 1-year treatment duration in men suffering from BPH/LUTS $[16,21]$.

Relief of symptoms was observed in all treatment groups, and similar response rates were found for pumpkin seed extract and placebo in the ITT set. However, the increased response to the extract observed in the PP analysis could indicate pharmacologic effects, since protocol violations that could have diminished the response had been excluded from that set.

Among the patients who received pumpkin seed, the response rate after 12 months was about $60 \%$. This exceeded the response to either form of capsule treatment by $10 \%$. The descriptive intergroup comparisons showed statistically significant differences.

Differences in cultivation and manufacturing processes mean that these results cannot be extrapolated to pumpkin seed preparations in general. Further investiga- tion of the components that contribute to the pharmacologic actions of the drug might explain possible differences in action between unprocessed pumpkin seed and the extract.

The possible contribution made by the patients' perception of the open-label treatment cannot fully explain the improvement in symptoms that was observed with pumpkin seed, since the observed effects are quite striking compared with those seen with any other conservative treatment of BPH/LUTS. Nearly $70 \%$ of the patients experienced a decrease of $\geq 3$ points on the IPSS, and nearly $60 \%$ of the patients reported a decrease of $\geq 5$ points. This response exceeds the rate of $43 \%$ reported by patients treated with herbal medicines in real-life practice in the TRIUMPH study [22]. The average IPSS reduction of 5.8 points that was achieved with pumpkin seed in the present study exceeds the placebo result by 1.4 points, whereas in studies of other herbal preparations, only a 1-point difference from placebo was observed $[16,23]$. The post- $/$ pre-treatment ratio of 0.66 for the IPSS in the pumpkin seed group represents a fair response and almost reaches the level of 0.6 indicating a good response according to the efficacy grading of the International Consultation on BPH [24].

The decrease in IPSS was accompanied by a continuous improvement in QoL score compared with baseline. As it is assumed that QoL might be less responsive than the IPSS, this observation is noteworthy. As irritative symptoms, which are the most prevalent LUTS in men [25], are more likely to affect QoL, the reduction in nocturia could account for a large part of this effect $[26,27]$. With pumpkin seed, a good response was also observed for urgency.

Consistent with previous observations, the incidence of drug-related adverse events was very low. No serious adverse events were attributed to the study medications. The PSA levels were not influenced.

\section{Conclusion}

This partially double-blinded, randomized study over 12 months compared pumpkin seed extract and pumpkin seed with placebo. The sample size of 1,431 randomized patients with BPH/LUTS by far exceeds the usual scale of controlled studies conducted on herbal and chemical drugs.

The findings of this study add to the evidence that treatment with pumpkin seed results in a substantial improvement in BPH/LUTS. The observed symptom relief 
is accompanied by a clinically significant improvement in IPSS-related QoL. The numerical improvements in IPSSrelated QoL and nocturia compared with baseline were greater in the pumpkin seed groups than in the placebo group. $\mathrm{Q}_{\max }$ increased in all groups.

Both pumpkin seed medications showed an excellent safety profile consistent with previous observations. Only 8 patients $(0.6 \%)$ reported treatment-emergent adverse events which were classified as possibly drug related. The objective of the treatment of uncomplicated $\mathrm{BPH}$ is to improve QoL by relieving the associated LUTS. The effects seen in this study with pumpkin seed suggest it could be recommended for patients with mild- to-moderate symptoms. However, this needs to be further substantiated in a confirmatory study or systematic review.

\section{Acknowledgements}

The authors thank Winicker Norimed, Nuremberg, Germany, for monitoring the study, data management and statistical analyses (the last performed by Dr. Thomas Fischer) and Dr. Hartmut Stuetzer, University of Cologne, Germany, for the blinded data review. They also thank the principal investigator, Dr. Peter MalsyMink, Munich, Germany, and all other investigators of the participating sites. The study was sponsored by GlaxoSmithKline Consumer Healthcare, Germany.

\section{References}

1 German Commission E: Cucurbitae peponis semen. Bundesanzeiger No 223, Nov 30, 1985, correction Bundesanzeiger No 11, Jan 17, 1991

2 Pater B: Über die Heilkraft des Kürbissamens. Heil Gewürzpfl 1929;12:18-20.

3 Committee on Herbal Medicinal Products (HMPC): Assessment report on Cucurbita pepo L., semen. EMA/HMPC/136022/2010, Nov 20, 2012, fist published March 25, 2013.

4 Nitsch-Fitz R, Egger H, Wutzl H, Maruna H Einsatz des Kürbiskern-Diätetikums 'KürbisGranufink' bei Patienten mit Prostatahypertrophie in Wiener Allgemeinpraxen. Erfahrungsheilkunde 1979;28:1009-1013.

5 Nitsch-Fitz R, Egger H, Wutzl H, Maruna H: Ergebnisse einer Praxisstudie über das Kürbiskern-Diätetikum 'Kürbis-Granufink' bei Patienten mit Miktionsbeschwerden verschiedener Genese. Dr Med 1979;3:38-40.

6 Strobl M, Patz B, Bracher F: Kürbissamen bei Störungen der Blasenfunktion. DAZ 2004; 144:4010-4014

7 Bracher F, Plössl F: Identification and determination of phytosterols in pharmaceutical preparations. Annu Meet DPhG (Deutsche Pharmazeutische Gesellschaft), Jena, 2009.

8 Abdel-Rahman MK: Effect of pumpkin seed (Cucurbita pepo L.) diets on benign prostatic hyperplasia (BPH): chemical and morphometric evaluation in rats. World J Chem 2006,1:33-40.

9 Gossell-Williams M, Davis A, O'Connor N: Inhibition of testosterone-induced hyperplasia of the prostate of Sprague-Dawley rats by pumpkin seed oil. J Med Food 2006;9:284-286.

10 Tsai YS, Tong YC, Cheng JT, Lee CH, Yang FS, Lee HY: Pumpkin seed oil and phytosterol-F can block testosterone/prazosin-induced prostate growth in rats. Urol Int 2006;77:269-274.

11 Zhang X, Ouyang J, Zhang Y, Tayalla B, Zhou $X$, Zhou S: Effect of the extracts of pumpkin seeds on the urodynamics of rabbits: an experimental study. J Tongji Med Univ 1994;14: 235-238.
12 Kim SH, Jung KI, Koh JS, Min KO, Cho SY, Kim HW: Lower urinary tract symptoms in benign prostatic hyperplasia patients: orchestrated by chronic prostatic inflammation and prostatic calculi? Urol Int 2013;90:144-149.

-13 Fahim AT, Abd-El-Fattah AA, Agha AM, Gad MZ: Effect of pumpkin-seed oil on the level of free radical scavengers induced during adjuvant-arthritis in rats. Pharmacol Res 1995;31:73-79.

14 Denis L, McConnell JD, Yoshica O, Khoury S, Abrams P, Barry M, et al: Recommendations of the International Scientific Committee: the evaluation and treatment of lower urinary tract syndromes (LUTS) suggestive of benign prostatic obstruction; in Denis L, Griffiths K, Khoury S, et al (eds): Proceedings of the 4th International Consultation on Benign Prostatic Hyperplasia (BPH). Plymouth, Plymbridge, 1998, pp 669-683.

15 Bach D: Placebokontrollierte Langzeitstudie mit Kürbissamenextrakt bei BPH-bedingten Miktionsbeschwerden. Urologe B 2000;40: 437-443; erratum in Urologe B 2001;41:42.

16 Madersbacher S, Marszalek M, Lackner J, Berger P, Schatzl G: The long-term outcome of medical therapy for BPH. Eur Urol 2007; 51:1522-1533.

17 MacDonald R, Tacklind JW, Rutks I, Wilt TJ: Serenoa repens monotherapy for benign prostatic hyperplasia (BPH): an updated Cochrane systematic review. BJU Int 2012;109: 1756-1761.

18 Adey GS, O'Leary MP, Barry MJ: Evaluating symptoms and functional status; in Kirby RS, McConnell JD, Fitzpatrick JM, Roehrborn CG, Boyle P (eds): Textbook of Benign Prostatic Hyperplasia. London, Tayler \& Francis, 2005, pp 201-209.

19 Dong Y, Hao L, Shi Z, Wang G, Zhang Z, Han C: Efficacy and safety of tadalafil monotherapy for lower urinary tract symptoms secondary to benign prostatic hyperplasia: a metaanalysis. Urol Int 2013;91:10-18.
20 Oelke M, Bachmann A, Descazeaud A, Emberton M, Gravas S, Michel MC, N'Dow J, Nordling J, de la Rosette JJ: EAU guidelines on the treatment and follow-up of non-neurogenic male lower urinary tract symptoms including benign prostatic obstruction. Eur Urol 2013;64:118-140.

21 Madersbacher S, Ponholzer A, Berger I, Marszalek M: Medical management of $\mathrm{BPH}$ : role of plant extracts. EAU EBU Update Ser 2007;5:197-205.

22 Hutchison A, Farmer R, Verhamme K, Berges $\mathrm{R}$, Navarrete RV: The efficacy of drugs for the treatment of LUTS/BPH, a study in 6 European countries. Eur Urol 2007;51:207-215.

23 Schneider T, Ruebben H: Stinging nettle root extract (Bazoton uno) in long term treatment of benign prostatic syndrome (BPS). Results of a randomized, double-blind, placebo-controlled multicenter study after 12 months (in German). Urologe A 2004;43: 302-306.

24 Homma Y, Kawabe K, Tsukamoto T, Tsukamoto R. Yamaguchi O, Okada K, Aso Y, Watanabe H, Okajima E, Kumazawa J, Yamaguchi T, Ohashi Y: Estimate criteria for efficacy of treatment in benign prostatic hyperplasia. Int J Urol 1996;3:267-273.

25 Konstantinidis C, Samainas M, Andreadakis S, Xanthis S, Skriapas K: Lower urinary tract symptoms associated with benign prostatic hyperplasia: combined treatment with fesoterodine fumarate extended-release and tamsulosin - a prospective study. Urol Int 2013;90:156-160.

-26 Săglam HS, Görkaya CS, Salar R, Memiş A, Adsan Ö: The effects of age, metabolic syndrome, nocturnal polyuria and sleep disorders on nocturia. Adv Clin Exp Med 2013;22: 489-494.

27 O'Leary MP: Validity of the 'bother score' in the evaluation and treatment of symptomatic benign prostatic hyperplasia. Rev Urol 2005; 7:1-10. 